\title{
Desprendimento e arraste do solo pelo escoamento superficial ${ }^{1}$
}

\author{
Silvio B. Pereira² ${ }^{2}$ Fernando F. Pruski ${ }^{3}$, Demetrius D. da Silva ${ }^{4}$ \& Antonio T. de Matos $^{5}$
}

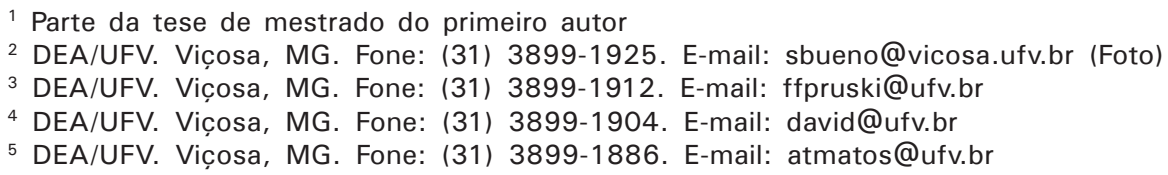

Protocolo 177 - 26/11/2002 - Aprovado em 5/9/2003

\begin{abstract}
Resumo: O presente trabalho teve como objetivo analisar o efeito de diferentes vazões de escoamento superficial e declividades nas perdas de solo resultantes. Na realização do experimento utilizou-se um canal, no qual foi colocada uma camada de solo (Latossolo Vermelho-Amarelo) com espessura de $12 \mathrm{~cm}$. Para a análise da capacidade de desprendimento e arraste de partículas de solo pelo escoamento superficial a aplicação de água foi feita de maneira uniforme ao longo de toda a largura do canal. Foram utilizadas as declividades de 2, 4, 6, 8 e 10\%, e seis vazões distintas para cada uma destas declividades. Em cada teste foi determinada a perda de solo pelo método direto e, com base nos dados de taxas de perdas de solo obtidos a partir das diferentes declividades e vazões de escoamento superficial utilizadas nos testes foram ajustadas equações de regressão. Os resultados obtidos permitiram as seguintes conclusões: a) a declividade apresentou um efeito mais expressivo nas taxas de perdas de solo do que a vazão; b) observouse tendência de declínio das taxas de perdas de solo com o tempo; e c) a equação linear foi a que melhor se ajustou aos dados de perdas de solo ao longo do tempo para a declividade de $2 \%$, enquanto, o ajuste da equação do tipo potencial se mostrou mais adequado para as declividades de 8 e 10\%. Nas declividades de 4 e $6 \%$, entretanto, não se observaram diferenças expressivas entre os ajustes das equações linear e potencial.
\end{abstract}

Palavras-chave: erosão hídrica, erosão em sulcos, perdas de solo

\section{Detachment and transport of soil by overland flow}

\begin{abstract}
The paper had the objective to analyze the effect of the overland flow and slope in the soil losses. A channel with a soil layer (Red Yellow Latosol) $12 \mathrm{~cm}$ deep was used. The water was applied in the channel in an uniform way. The slopes used were 2, 4, 6, 8 and $10 \%$ and for each one of these slopes six different overland flow values were used. The soil loss was measured by the direct method. Using the soil loss rates measured and the values of slope and overland flow a regression equation was adjusted. The obtained results allowed the following conclusions: a) the slope had a more significant effect in the soil loss rate than the discharge; b) tendency of decline of the rates of soil loss was observed with the time; and c) the linear equation was better adjusted to the data of soil loss for the slope of $2 \%$, while the adjustment of the equation of the potential type was better for slopes of 8 and $10 \%$. For slopes of 4 and $6 \%$, however, no significant differences were observed between the linear and potential equation.
\end{abstract}

Key words: overland flow, rill erosion, soil loss

\section{INTRODUÇÃO}

A erosão consiste no processo de desprendimento e arraste das partículas de solo causado pela ação da água (erosão hídrica) ou do vento (erosão eólica). No Brasil, localizado em grande parte na região tropical, a erosão hídrica apresenta maior interesse por ser de ocorrência mais freqüente, processar-se com maior rapidez e causar grandes prejuízos não só ao setor agrícola, como também a diversas outras atividades econômicas e ao próprio meio ambiente.
A erosão hídrica ocorre quando há ruptura do equilíbrio natural existente no solo, e as forças advindas de fatores climáticos, como a chuva e o vento, passam a ser suficientes para desequilibrar esse sistema. Associadas a outros fatores relativos às condições do terreno sobre o qual a chuva incide, essas forças determinam a intensidade do processo erosivo. Dentre os fatores relacionados às condições do terreno que interferem no processo erosivo, destacam-se a declividade, a capacidade de infiltração de água no solo, a distância percorrida pelo escoamento superficial, a rugosidade superficial, a 
resistência do solo à ação erosiva da chuva e a percentagem de cobertura do solo existente à época da ocorrência da chuva.

Na modelagem para predição das perdas de solo, a erosão é separada em erosão entre sulcos e erosão em sulcos. A erosão entre sulcos é descrita como o processo de desprendimento das partículas de solo pelo impacto das gotas da chuva, pelo transporte no escoamento de lâmina rasa e pela liberação de sedimentos para os pequenos sulcos ou canais. A erosão no sulco é função da capacidade do escoamento em desprender os sedimentos, da capacidade de transporte do escoamento e da carga de sedimentos existentes no escoamento (Flanagam et al., 1995), sendo a maior parte do solo perdida em pequenos sulcos que se formam em decorrência do escoamento superficial (Tiscareno Lopez et al., 1993).

Com a concentração do escoamento em sulcos desenvolvese uma tensão cisalhante no perímetro molhado do sulco que pode desprender partículas de solo. A taxa de desagregação varia conforme o tipo e manejo do solo e é diretamente proporcional à erodibilidade do solo e à diferença entre a tensão cisalhante associada ao escoamento e a tensão crítica de cisalhamento do solo. Foster (1982) descreveu essa relação com a equação

$$
\mathrm{D}_{\mathrm{r}}=\mathrm{K}_{\mathrm{r}}\left(\tau-\tau_{\mathrm{c}}\right)
$$

em que:

$\mathrm{D}_{\mathrm{r}} \quad$ - taxa de desagregação do solo em sulcos, $\mathrm{kg} \mathrm{s}^{-1} \mathrm{~m}^{-2}$

$\mathrm{K}_{\mathrm{r}} \quad$ - Fator de erodibilidade do solo em sulcos, $\mathrm{s} \mathrm{m}^{-1}$

$\tau$ - tensão cisalhante associado ao escoamento, $\mathrm{N} \mathrm{m}^{-2}$

$\tau_{c} \quad$ - tensão crítica de cisalhamento do solo, $\mathrm{N} \mathrm{m}^{-2}$

Com base neste enfoque, o presente trabalho teve como objetivo analisar o efeito de diferentes vazões de escoamento superficial e declividades da superfície sobre as perdas de solo resultantes.

\section{MATERIAL E MÉTODOS}

O presente trabalho foi conduzido no Laboratório de Hidráulica do Departamento de Engenharia Agrícola da Universidade Federal de Viçosa. Para o cumprimento do objetivo proposto, foi necessário o desenvolvimento e a construção de um canal de solo, conforme é descrito na seqüência.

\section{Desenvolvimento e construção do canal de solo}

Na Figura 1 estão apresentadas uma visão geral do canal de solo (a), construído para o estudo da capacidade de desprendimento e arraste de partículas de solo em decorrência do escoamento superficial e, de forma esquemática, uma vista lateral do canal, mostrando suas estruturas básicas com as respectivas dimensões (b).

O canal de solo é constituído das estruturas básicas descritas a seguir: a) estrutura de sustentação, constituída de dois cavaletes, sendo em um deles montada uma estrutura de sustentação equipada com sistema telescópio, para permitir a
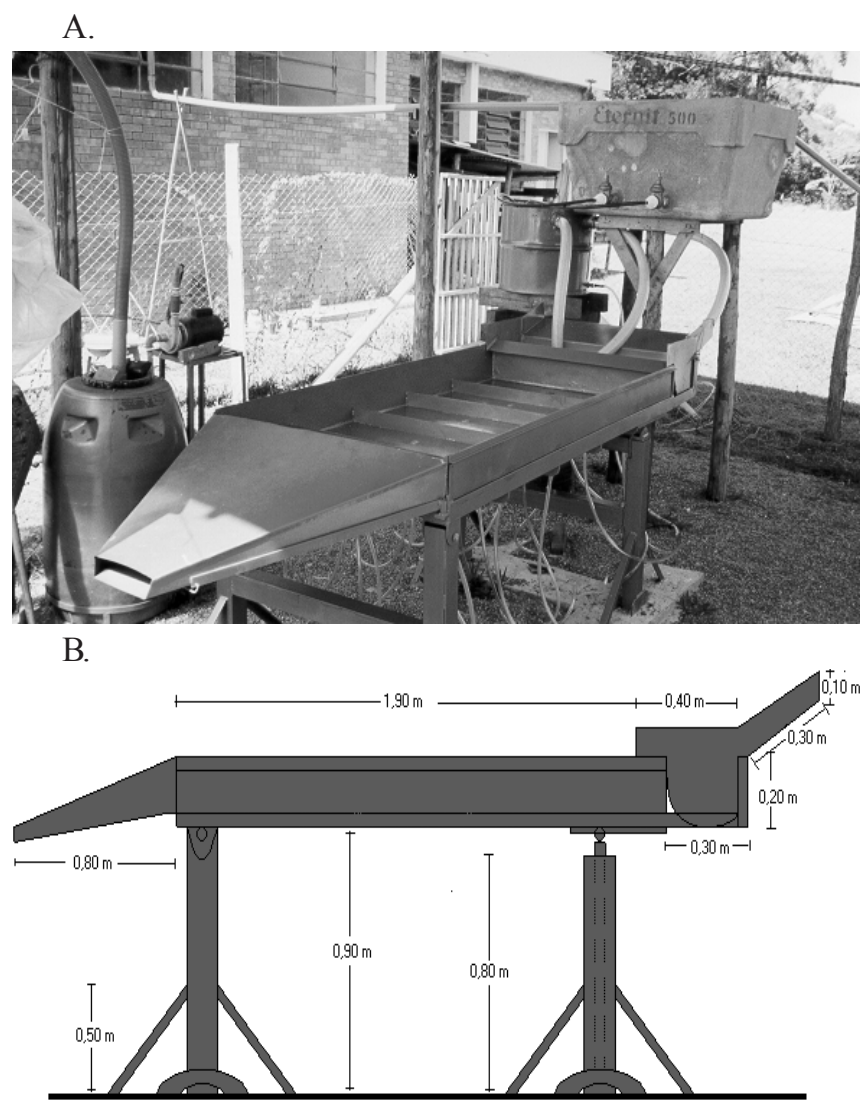

Figura 1. Vista geral (A) e vista esquemática lateral (B) do canal de solo

variação da declividade do canal com o uso de um macaco hidráulico; b) caixa de contenção de solo (canal de solo propriamente dito) com 2,0 m de comprimento, 1,0 m de largura e $0,2 \mathrm{~m}$ de profundidade. Nesta caixa foram fixadas, no seu fundo, chapas transversais ao sentido da declividade para evitar o escoamento rente ao fundo da caixa e, dessa forma, proporcionar que todo escoamento ocorresse na superfície do solo; c) sistema de drenagem, constituído de tubos de cobre inseridos no fundo do canal para facilitar a saída do ar quando da saturação do solo; e d) sistema de aplicação uniforme de água ao longo de toda a largura do canal, constituído de dispositivos que permitem manter a vazão constante ao longo do experimento.

\section{Descrição do experimento}

Para a execução dos testes foi colocada no canal uma camada de solo (Latossolo Vermelho-Amarelo) com espessura de aproximadamente $12 \mathrm{~cm}$. O solo foi passado em peneira de $4,5 \mathrm{~mm}$, após ser seco ao ar por um período de dois dias, e posteriormente acomodado sobre o canal em três camadas de $4 \mathrm{~cm}$ cada uma, realizando-se a compactação de modo que a densidade do solo no canal se aproximasse da existente no campo.

Entre o fundo do canal e a camada de solo foi colocada uma camada de areia de $3 \mathrm{~cm}$, para facilitar a drenagem da água aplicada durante o preparo do solo no canal. Para separar a camada de areia da primeira camada de solo foi colocada uma manta sintética de alta permeabilidade. 
Para a análise da capacidade de desprendimento e arraste de partículas do solo pelo escoamento superficial, a aplicação de água no canal foi feita de forma uniforme, ao longo de toda a largura do canal, por meio de uma calha e de dispositivos que permitiram manter a vazão constante ao longo de todo o teste. Sabendo-se que a condição crítica para a ocorrência de escoamento superficial e perdas de solo é aquela em que o solo se encontra saturado, procedeu-se, antes do início dos testes, à aplicação de uma lâmina d'água de aproximadamente $100 \mathrm{~mm}$ para saturação do solo.

Foram utilizadas as declividades de 2, 4, 6, 8 e $10 \%$ e seis vazões distintas para cada uma das declividades conforme apresentadas no Tabela 1 .

Tabela 1. Vazões utilizadas no experimento para cada uma das declividades estudadas

\begin{tabular}{cllllll}
\hline Declividade (\%) & \multicolumn{7}{c}{ Vazões $\left(\mathrm{L} \mathrm{s}^{-1}\right)$} \\
\hline 2 & 0,63 & 0,76 & 0,82 & 0,91 & 0,99 & 1,11 \\
4 & 0,52 & 0,64 & 0,66 & 0,75 & 0,82 & 0,96 \\
6 & 0,44 & 0,56 & 0,57 & 0,65 & 0,72 & 0,84 \\
8 & 0,42 & 0,50 & 0,53 & 0,60 & 0,65 & 0,77 \\
10 & 0,39 & 0,46 & 0,48 & 0,55 & 0,57 & 0,70 \\
\hline
\end{tabular}

Em cada teste foi determinada a perda de solo, pelo método direto, realizando-se a coleta do solo a cada intervalo de dois minutos, por um período de 30 segundos, sendo feitas coletas por um período máximo de 30 minutos. A determinação da geometria do perfil do solo presente no canal foi feita antes e depois da aplicação da vazão de escoamento superficial, com o uso de um perfilômetro equipado com 40 varetas espaçadas de $2,5 \mathrm{~cm}$ entre si em 10 seções transversais à declividade do canal de solo, obtendo-se um total de 400 pontos de leitura da microtopografia da superfície do solo. Com base nos dados de taxas de perdas de solo obtidos a partir das diferentes declividades e vazões de escoamento superficial utilizadas nos testes foram ajustadas equações de regressão.

\section{RESULTADOS E DISCUSSÃO}

Com base nos dados de taxas de perdas de solo $\left(\mathrm{T}_{\mathrm{PS}}\right.$, em $\mathrm{kg} \mathrm{m}^{-2} \mathrm{~min}^{-1}$ ) obtidos a partir das diferentes declividades (S, em $\%$ e vazões de escoamento superficial (Q, em L s ${ }^{-1}$ ) utilizadas nos testes, foram ajustadas equações de regressão com tendências linear e potencial, as quais são apresentadas a seguir:

$$
\begin{gathered}
\mathrm{T}_{\mathrm{PS}}=-1,8437+0,3395 \mathrm{~S}+1,4653 \mathrm{Q} \\
\left(\mathrm{R}^{2}{ }_{\text {aj }}=0,84\right)
\end{gathered}
$$

$$
\begin{gathered}
\mathrm{T}_{\mathrm{PS}}=0,0268 \mathrm{~S}^{2,2248} \mathrm{Q}^{0,9102} \\
\left(\mathrm{R}_{\text {aj }}^{2}=0,93\right)
\end{gathered}
$$

Tanto pela análise da Eq. 2 quanto da Eq. 3, pode-se evidenciar que a taxa de perda de solo cresce com o aumento da vazão e da declividade. Constata-se, também, que a equação potencial proporcionou um melhor ajuste que a linear quando o expoente relativo à vazão aproximou-se da unidade e o expoente relativo à declividade aproximou-se de dois, evidenciando-se uma influência mais expressiva da declividade nas taxas de perda de solo do que a decorrente da vazão, conforme também foi evidenciado por diversos autores, como Meyer et al. (1983) e Watson \& Laflen (1986), que afirmaram que a perda de solo aumenta com a elevação da declividade e, em menor escala, com o aumento da vazão.

$\mathrm{Na}$ Tabela 2 apresentam-se os valores médios das taxas de perdas de solo em função de diferentes declividades e vazões de escoamento superficial. Embora pelas Eqs. 2 e 3 se observe a tendência de crescimento das taxas de perdas de solo com o aumento da vazão e, em maior proporção, da declividade, na Tabela 2 evidencia-se que houveram testes em que essa tendência não foi observada de forma tão clara.

Observando as taxas de perdas de solo (Tabela 2) obtidas nas diversas vazões de escoamento superficial testadas para a declividade de $2 \%$ evidenciou-se que não houve uma influência bem definida das vazões aplicadas nas taxas de perdas de solo. Verificou-se que a maior taxa de perda de solo $\left(0,38 \mathrm{~kg} \mathrm{~m}^{-2} \mathrm{~min}^{-1}\right)$ se deu com a vazão de $0,99 \mathrm{~L} \mathrm{~s}^{-1}$, o que pode ser explicado pela ocorrência de maior concentração do escoamento superficial em sulcos, ocasionando, conseqüentemente, a formação de caminhos preferenciais de escoamento da água e aumentando, com isso, a tensão cisalhante associada ao escoamento superficial.

A menor taxa de perda de solo $\left(0,22 \mathrm{~kg} \mathrm{~m}^{-2} \mathrm{~min}^{-1}\right)$ também não ocorreu com a menor vazão, sendo observada na vazão de $0,82 \mathrm{~L} \mathrm{~s}^{-1}$, caracterizando a influência da forma com que se processa o processo erosivo nas perdas de solo resultantes, uma vez que neste teste se observou menor concentração do escoamento superficial em sulcos.

Nas Figuras de 2 a 6 estão representadas as variações das taxas de perdas de solo obtidas pela união dos pontos encontrados experimentalmente (A), e das perdas acumuladas de solo em função do tempo de duração do teste com as respectivas equações ajustadas a partir de tendências potencial (B) e linear (C), nas declividades de 2, 4, 6, 8 e $10 \%$, respectivamente. Os testes com declividades de 6,8 e 10\% apresentaram redução do seu tempo de duração em função de já ter sido atingida,

\begin{tabular}{|c|c|c|c|c|c|c|c|c|c|c|c|c|c|c|}
\hline S & Q & $\mathrm{T}_{\mathrm{PS}}$ & S & Q & $\mathrm{T}_{\mathrm{PS}}$ & S & Q & $\mathrm{T}_{\mathrm{PS}}$ & S & Q & $\mathrm{T}_{\mathrm{PS}}$ & $\mathrm{S}$ & Q & $\mathrm{T}_{\mathrm{PS}}$ \\
\hline \multirow{6}{*}{2} & 0,63 & 0,27 & \multirow{6}{*}{4} & 0,52 & 0,45 & \multirow{6}{*}{6} & 0,44 & 0,51 & \multirow{6}{*}{8} & 0,42 & 1,63 & \multirow{6}{*}{10} & 0,40 & 1,73 \\
\hline & 0,76 & 0,24 & & 0,64 & 0,46 & & 0,56 & 1,41 & & 0,50 & 1,22 & & 0,46 & 2,34 \\
\hline & 0,82 & 0,22 & & 0,66 & 0,46 & & 0,57 & 0,85 & & 0,53 & 1,30 & & 0,48 & 2,37 \\
\hline & 0,91 & 0,24 & & 0,75 & 0,49 & & 0,65 & 0,88 & & 0,60 & 1,85 & & 0,55 & 2,75 \\
\hline & 0,99 & 0,38 & & 0,82 & 0,59 & & 0,72 & 0,91 & & 0,65 & 1,32 & & 0,57 & 2,48 \\
\hline & 1,11 & 0,30 & & 0,96 & 0,77 & & 0,84 & 1,16 & & 0,77 & 1,71 & & 0,70 & 3,78 \\
\hline
\end{tabular}
nesses tempos, a camada em que se encontrava a manta

Tabela 2. Valores médios de taxas de perda de solo $\left(\mathrm{T}_{\mathrm{pS}}\right.$, em kg m $\left.\mathrm{min}^{-1}\right)$ obtidas para diferentes declividades ( $\mathrm{S}$, em \%) e vazões de escoamento superficial $\left(\mathrm{Q}, \mathrm{em} \mathrm{L} \mathrm{s}^{-1}\right)$ 


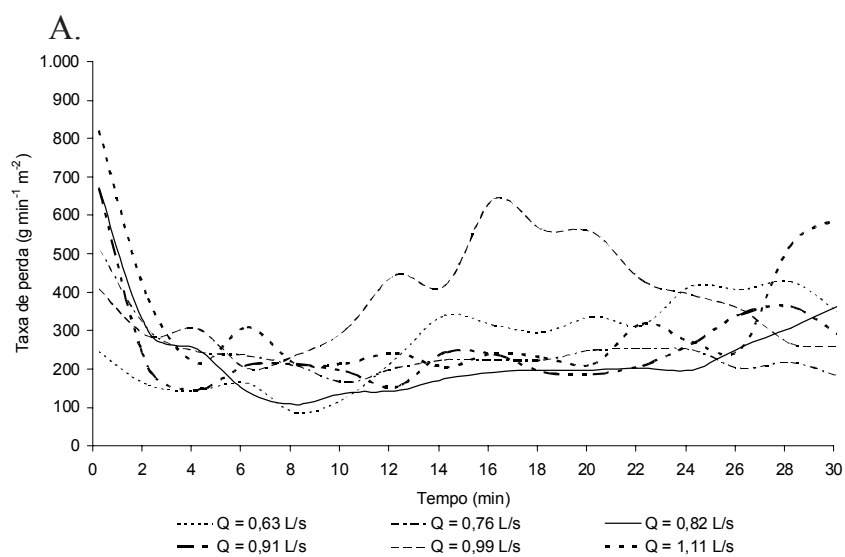

B.
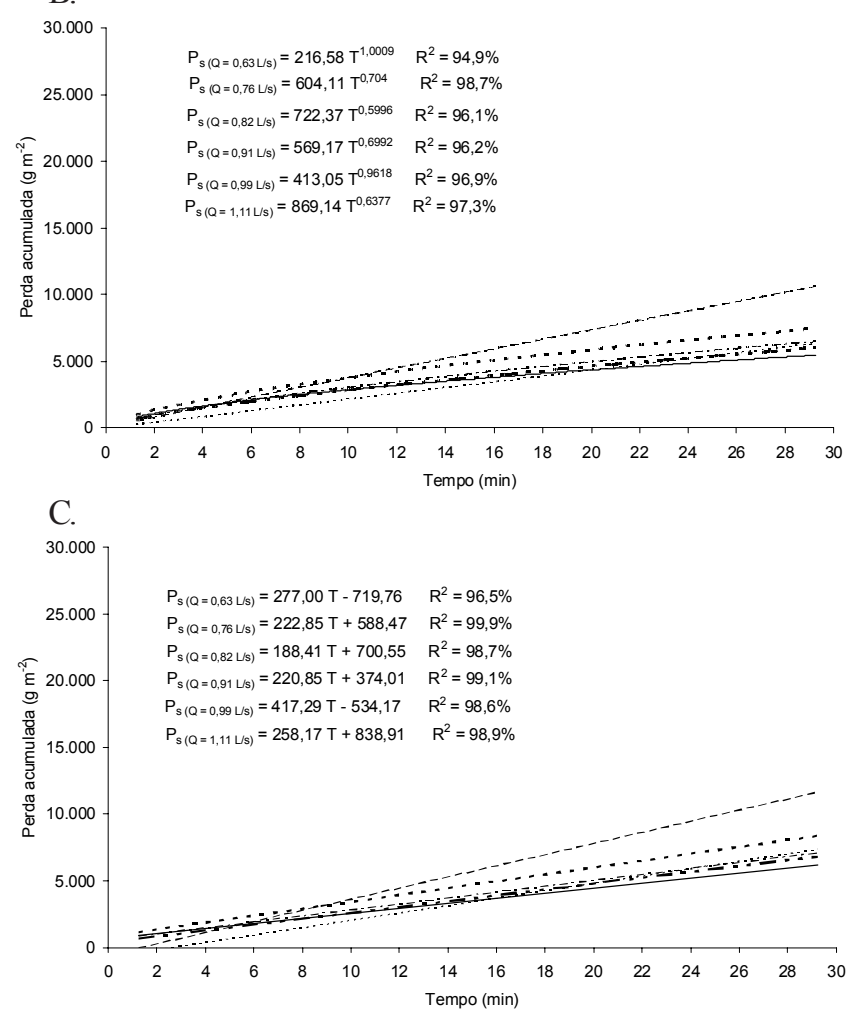

Figura 2. Perdas de solo em função do tempo para a declividade de $2 \%$ : expressas em termos de taxa (A); em valores acumulados ajustados a partir de uma equação potencial (B) e em valores acumulados linearizados (C)

sintética usada para separar o solo da camada de areia colocada no fundo do canal.

Na Figura 2A (declividade de 2\%) evidencia-se uma redução nas taxas de perdas de solo da primeira para a segunda coleta, tendendo à estabilização a partir da segunda coleta, indicando que a taxa de perda de solo tornou-se aproximadamente constante ao longo do tempo, o que pode ser explicado pelo fato de que a diferença entre a tensão cisalhante associada ao escoamento e a tensão crítica de cisalhamento do solo (Eq. 1) tenha se tornado constante ao longo do teste, o que, conseqüentemente, ocasionou taxa de perda de solo também constante com o tempo.

Na Figura 3 (declividade de 4\%) observou-se, de forma clara, a influência das vazões de escoamento superficial aplicadas nas taxas de perdas de solo, uma vez que houve
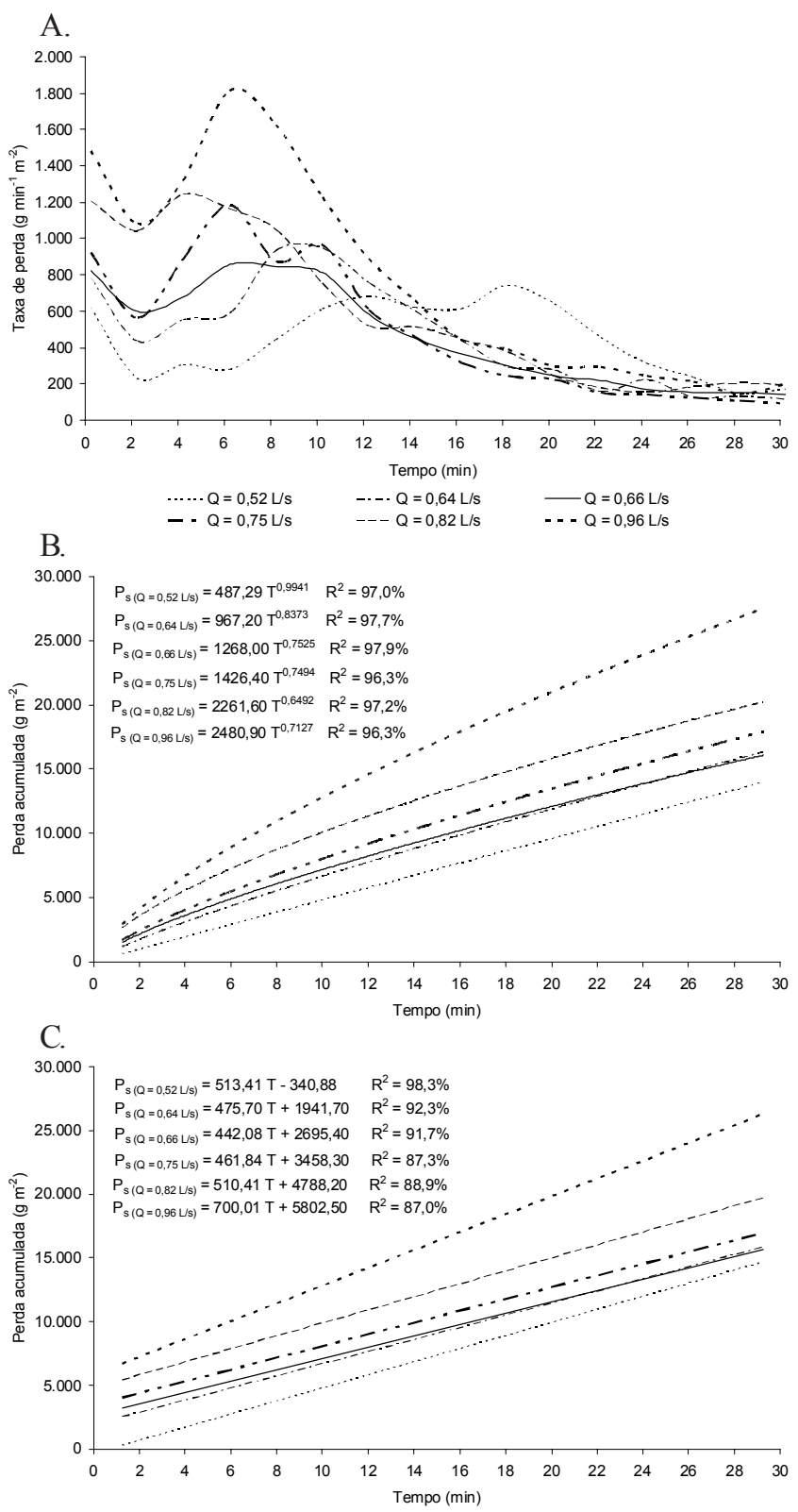

Figura 3. Perdas de solo em função do tempo para a declividade de 4\%: expressas em termos de taxa (A); em valores acumulados ajustados a partir de uma equação potencial (B) e em valores acumulados linearizados (C)

elevação destas com o aumento das vazões. Essa mesma tendência foi observada nas declividades de 6 e $10 \%$, entretanto, na declividade de $6 \%$ verificou-se que a vazão de escoamento superficial de $0,56 \mathrm{~L} \mathrm{~s}^{-1}$ apresentou taxa de perda de solo bem superior à dos demais testes, não sendo encontrada nenhuma explicação concreta para esse comportamento. Verificou-se, também, uma redução das taxas de perdas de solo da primeira para a segunda coleta, na declividade de $4 \%$, com a ressalva de que, a partir desta declividade, já se evidenciou a formação de caminhos preferenciais de escoamento da água a partir da segunda coleta. Com a continuação do teste, foi evidenciada uma tendência de redução e posterior estabilização.

Na declividade de 6\% (Figura 4), a estabilização das taxas de perdas de solo tendeu a ocorrer em um tempo menor, em 


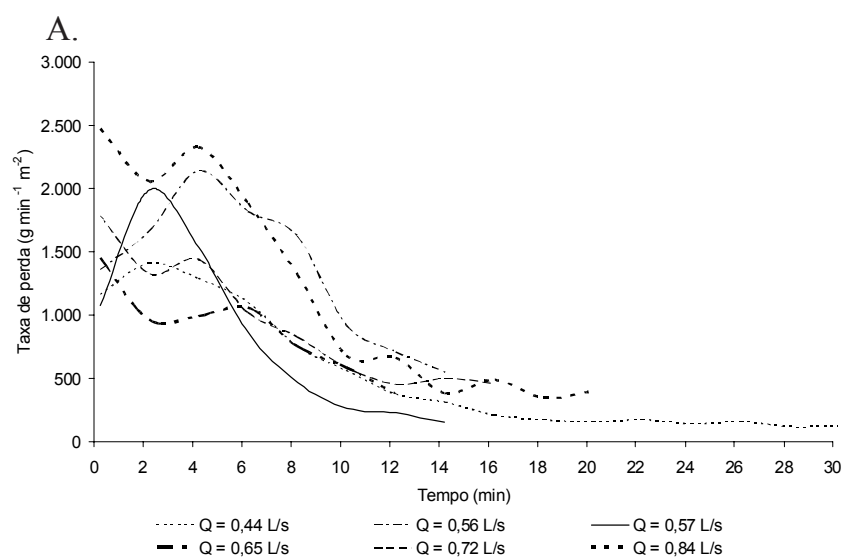

B.
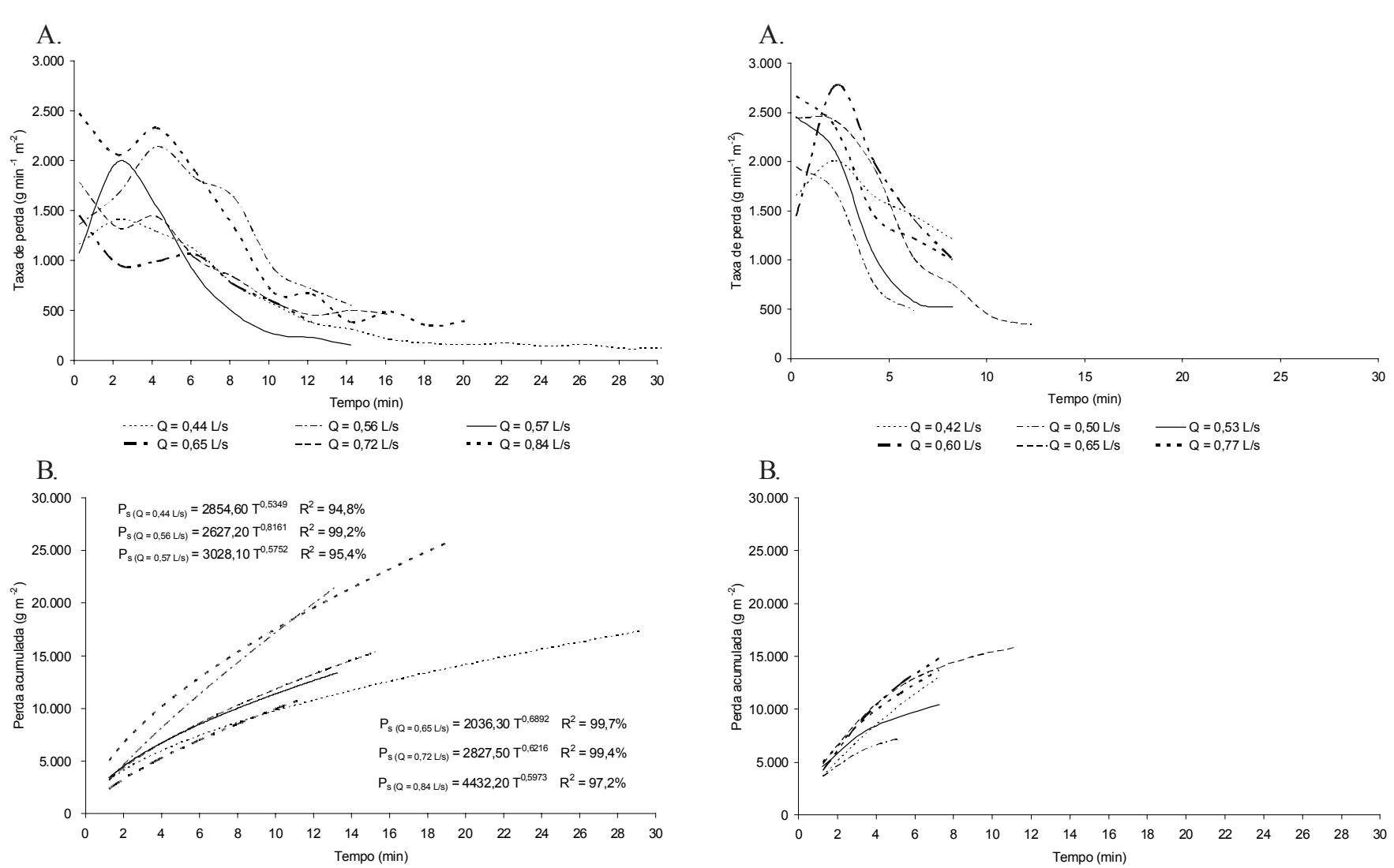

$$
\text { C. }
$$

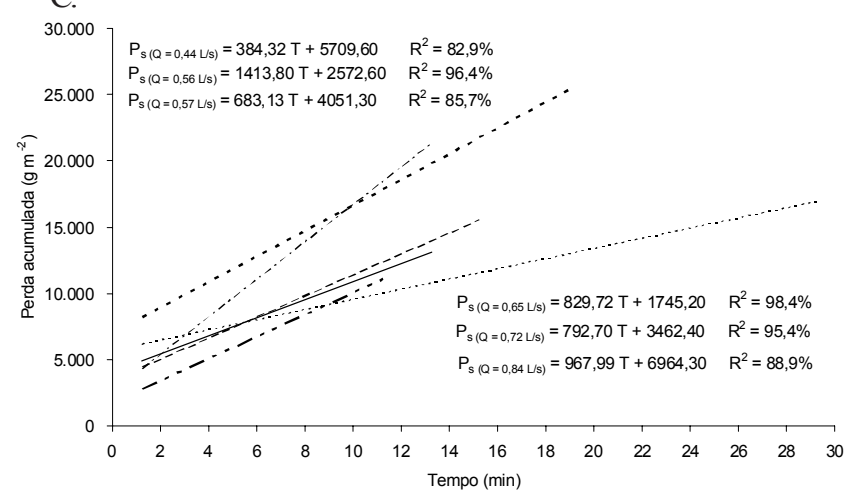

Figura 4. Perdas de solo em função do tempo para a declividade de 6\%: expressas em termos de taxa (A); em valores acumulados ajustados a partir de uma equação potencial (B) e em valores acumulados linearizados (C)

comparação com a declividade de $4 \%$, entretanto a concentração do escoamento e a conseqüente formação de sulcos profundos, fez com que o teste tivesse que ser paralisado antes da duração prevista (30 min), pois foi atingida a camada de manta sintética colocada para separar o solo da camada de areia.

Na declividade de $8 \%$ (Tabela 2 e Figura 5) evidenciou-se, da mesma forma que na declividade de $2 \%$, que não houve influência nítida das vazões de escoamento superficial aplicadas nas taxas de perdas de solo. Assim, observou-se que a maior taxa $\left(1,85 \mathrm{~kg} \mathrm{~m}^{-2} \mathrm{~min}^{-1}\right)$ ocorreu com a vazão de $0,60 \mathrm{~L} \mathrm{~s}^{-1}$, o que pode ser explicado pela influência decorrente do processo de concentração do escoamento superficial em sulcos, que interfere expressivamente na capacidade de desprendimento e transporte de sedimentos, à medida que promove aumento da

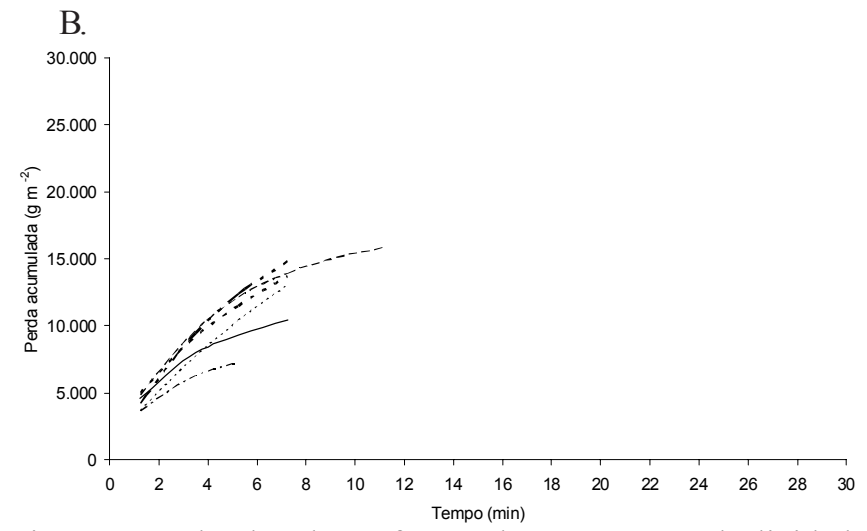

Figura 5. Perdas de solo em função do tempo para a declividade de 8\%: expressas em termos de taxa (A); e em valores acumulados (B)
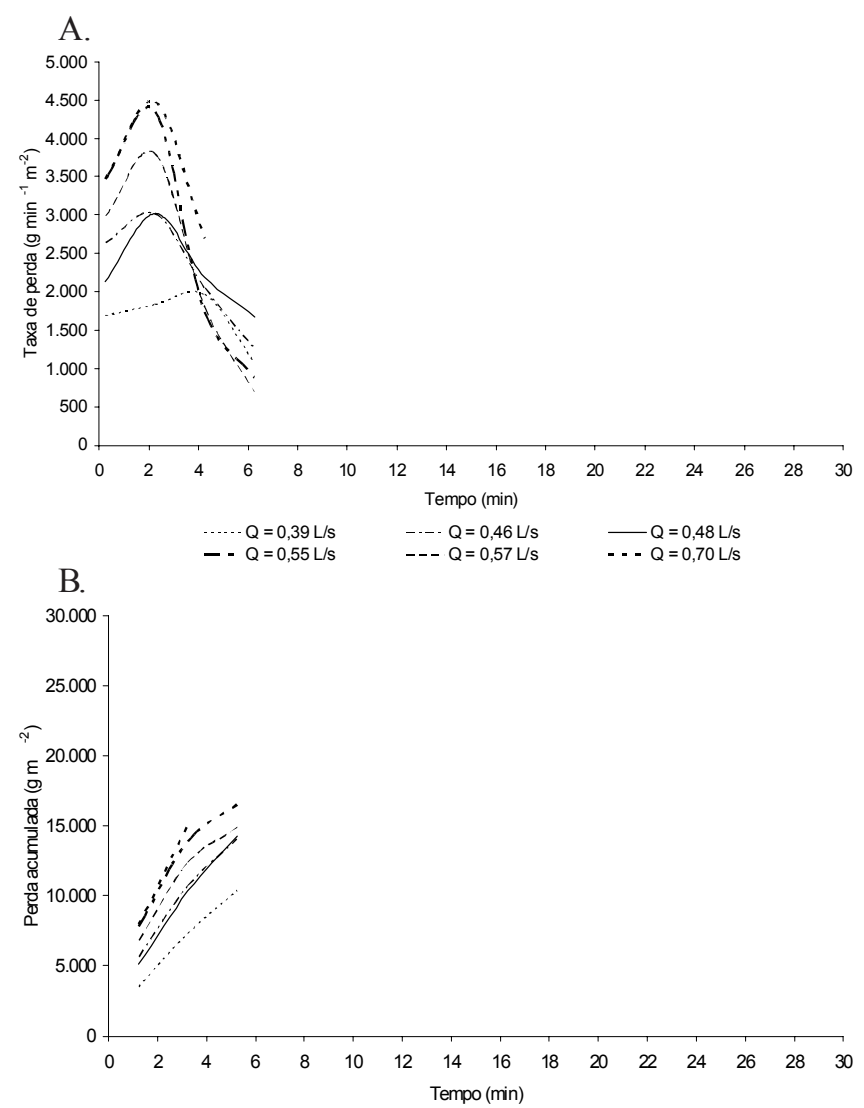

Figura 6. Perdas de solo em função do tempo para a declividade de 10\%: expressas em termos de taxa (A) e em valores acumulados (B) 
tensão cisalhante associada ao escoamento e, conseqüentemente, na capacidade de transporte de sedimentos.

Nas Figuras 5 e 6 observou-se que o processo erosivo ocorreu de uma forma mais intensa, em decorrência da rápida concentração do escoamento, com a conseqüente formação de caminhos preferenciais de escoamento ocorrida nas declividades de 8 e $10 \%$. Dessa forma, evidenciou-se que, enquanto nas declividades de 2, 4 e 6\% houve estabilização das taxas de perdas de solo ao longo do teste, nas declividades de 8 e $10 \%$ não foi caracterizada a estabilização das taxas de perdas de solo, uma vez que houve a necessidade de paralisação do teste quando foi atingida a camada em que estava situada a manta sintética.

Evidencia-se também que, enquanto na declividade de 2\% o melhor ajuste foi o linear, nas declividades de 6, 8 e 10\%, o melhor ajuste foi o potencial. Já na declividade de $4 \%$, tanto o ajuste potencial como o linear se mostraram apropriados.

Na Figura 7 mostra-se a geometria da superfície do solo no canal após os testes realizados na declividade de $2 \%$ com as vazões de escoamento superficial de 0,82 e $0,99 \mathrm{~L} \mathrm{~s}^{-1}$, evidenciando-se que, na vazão de escoamento superficial de $0,82 \mathrm{~L} \mathrm{~s}^{-1}$ ocorreu menor concentração do escoamento superficial em caminhos preferenciais, em comparação com a vazão de $0,99 \mathrm{~L} \mathrm{~s}^{-1}$. Observa-se, inclusive, pela análise dessa figura que, enquanto no teste realizado com a vazão de $0,82 \mathrm{~L} \mathrm{~s}^{-1}$ houve a formação de apenas um canal largo, no teste realizado com a vazão de $0,99 \mathrm{~L} \mathrm{~s}^{-1}$ houve a formação de dois sulcos decorrentes do escoamento superficial da água.

Comparando-se o teste com $2 \%$ de declividade e vazão de escoamento superficial de $0,63 \mathrm{~L} \mathrm{~s}^{-1}$ com o teste realizado com $10 \%$ de declividade e vazão de escoamento superficial de

A.

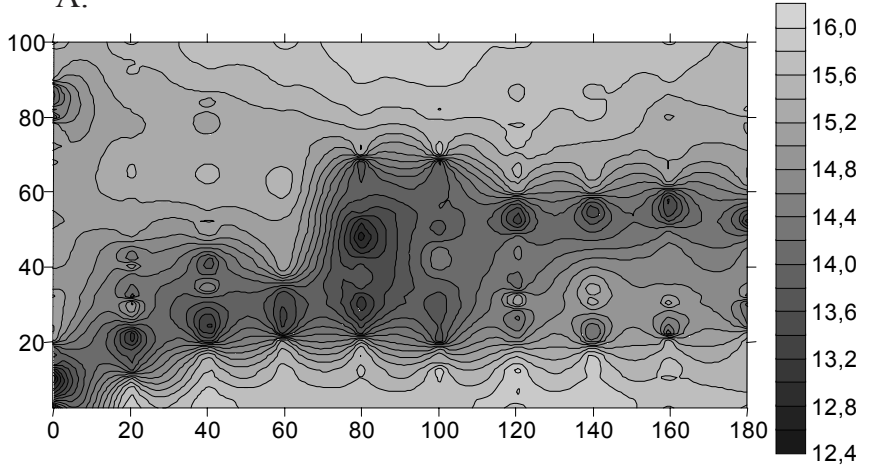

B.

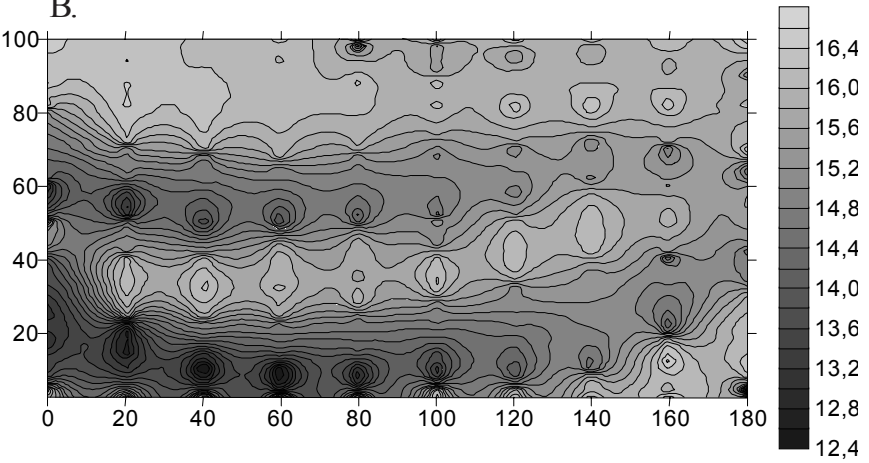

Figura 7. Geometria da superfície do solo no canal após os testes realizados na declividade de $2 \%$ com as vazões de escoamento superficial de: (A) $0,82 \mathrm{~L} \mathrm{~s}^{-1} \mathrm{e}$ (B) $0,99 \mathrm{~L} \mathrm{~s}^{-1}$

0,70 $\mathrm{L} \mathrm{s}^{-1}$, verificou-se aumento das taxas de perda de solo observadas nas condições extremas da ordem de 14 vezes (Figura 8). Isso caracterizou a grande influência da declividade sobre as taxas de perdas de solo produzidas, uma vez que a variação entre as duas vazões comparadas foi de apenas $10 \%$.

A.

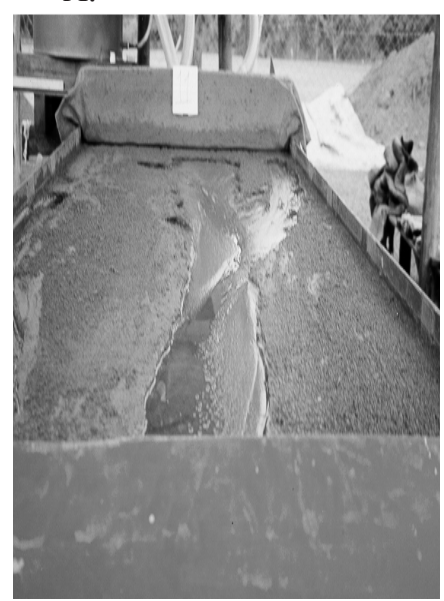

B.

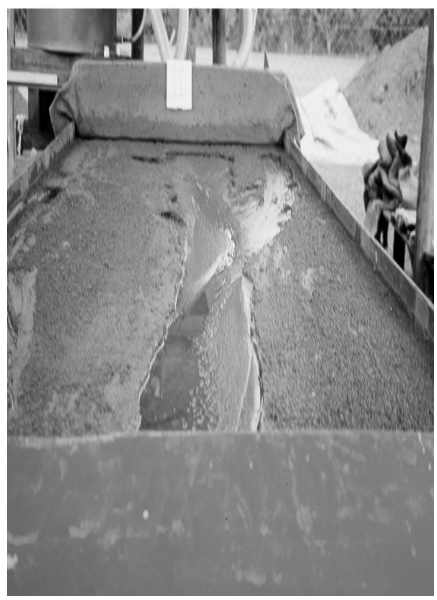

Figura 8. Vista da superfície do solo no canal após os testes realizados com: (A) declividade de $2 \%$ e vazão de escoamento superficial de $0,63 \mathrm{~L} \mathrm{~s}^{-1}$ e (B) declividade de $10 \%$ e vazão de escoamento superficial de $0,70 \mathrm{~L} \mathrm{~s}^{-1}$

Observa-se na Figura 8 que, em decorrência da concentração do escoamento superficial, começa a ocorrer a formação de caminhos preferenciais de escoamento que vão sofrendo aumento da sua profundidade com o transcorrer do tempo, o que provoca aumento também do raio hidráulico e, em conseqüências, a elevação da tensão cisalhante associada ao escoamento, aumentando também as perdas de solo no sulco. $\mathrm{O}$ alargamento do sulco, que promoveu redução do raio hidráulico, é evidenciado no teste com declividade de $2 \%$ e vazão de $0,63 \mathrm{~L} \mathrm{~s}^{-1}$, o qual apresentou um tempo de duração de 30 min e a formação de apenas um sulco. Na declividade de $10 \%$ e vazão de $0,70 \mathrm{~L} \mathrm{~s}^{-1}$, entretanto, o processo erosivo ocorreu rapidamente, promovendo a concentração do escoamento superficial e a formação de três sulcos, o que fez com que o teste tivesse que ser paralisado com o tempo de duração de aproximadamente quatro minutos pois, nesse tempo, 
foi atingida a camada em que se encontrava a manta sintética colocada para separar o solo da camada de areia.

Jennings et al. (1987) e Proffitt et al. (1993) também evidenciaram a tendência de decréscimo nas taxas de erosão em sulcos com o tempo. Foster (1982) e Brow (1988) atribuíram este decréscimo ao fato de o aprofundamento do sulco fazer com que sejam atingidas camadas de solo mais resistentes e, portanto, menos erodíveis. No presente estudo ocorreu decréscimo das taxas de perdas de solo com o tempo em todas as vazões de escoamento superficial aplicadas e em todas as declividades. Há de se considerar, entretanto, que nos testes não foi possível atingir uma camada menos erodível, em virtude da pequena profundidade do canal utilizado e do fato de todas as camadas receberem o mesmo tratamento de compactação. Portanto, o efeito evidenciado na redução das taxas de perdas de solo em sulcos foi devido à redução da tensão cisalhante associada ao escoamento ao longo do teste, o que ocorreu em virtude das alterações evidenciadas na geometria do sulco ao longo dos testes, promovendo redução do seu raio hidráulico.

\section{CONCLUSÕES}

1. A declividade apresentou um efeito mais expressivo nas taxas de perdas de solo do que a vazão.

2. Observou-se tendência de declínio das taxas de perdas de solo com o tempo.

3. A equação linear foi a que melhor se ajustou aos dados de perdas de solo ao longo do tempo para a declividade de $2 \%$, enquanto, o ajuste da equação do tipo potencial se mostrou mais adequado para as declividades de 8 e 10\%. Nas declividades de 4 e $6 \%$, entretanto, não se observaram diferenças expressivas entre os ajustes das equações linear e potencial.

\section{LITERATURA CITADA}

Brow, L.C. Effects of incorporated crop residue on rill erosion. West Lafayette: Purdue University, 1988, 197p. PhD Thesis

Flanagam, D. C.; Ascogh Ii, J. C.; Nicks, A. D.; Nearing, M. A.; Laflen, J. M. Overview of the WEPP erosion prediction model. In: USDA. Water erosion prediction project - WEPP. West Laffayete: 1995. Technical documentation, NSERL, Report No. 10

Foster, G.R. Modelling the erosion process. In: Haan, C.T.; Johnson, H.P.; Brakensienk, D.L. (eds.) Hydrologic modelling of small watersheds. Michigam: ASAE, 1982. p.296-380. ASAE Monograph, 5

Jennings, G. D.; Jarrett, A. R.; Hoover, J. R. Simulated rainfall duration and sequencing affect soil loss. Transactions of the ASAE, St. Joseph, v.30, n.1, p.158-161, 1987.

Meyer, L. D.; Zuhdi, B.A.; Coleman, N. L.; Prasad, S. N. Transport of sand-size sediment along crop row furrows. Transactions of the ASAE, St. Joseph, v.26, n.1, p.106-111, 1983.

Proffitt, A. P. B.; Hairsine, P. B.; Rose, C. W. Modeling soil erosion by overland flow: application over a range of hydraulic conditions. Transactions of the ASAE, St. Joseph, v.36, n.6, p.1743-1753, 1993.

Tiscareno-Lopez, M.; Lopes, V. L.; Stone, J. J.; Lane, L. J. Sensitivity analysis of the WEPP watershed model for rangeland applications. I: Hill slope processes. Transactions of the ASAE, St. Joseph, v.36, n.6, p.1659-1672, 1993.

Watson, D. A.; Laflen, J. M. Soil strength, slope and rainfall intensity effects on interrill erosion. Transactions of the ASAE, St. Joseph, v.29, n.1, p.98-102, 1986. 